
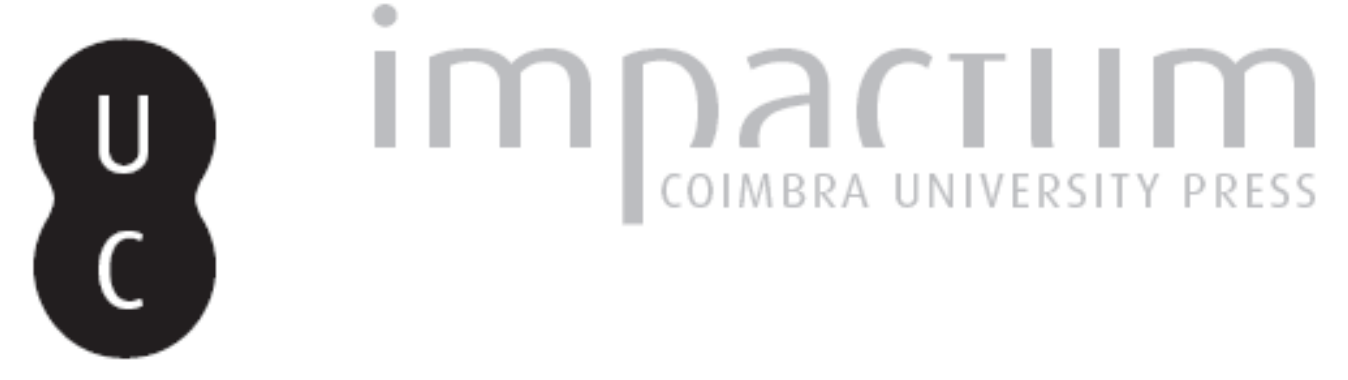

\title{
[Recensão a] Brandão, José Luís Lopes - Máscaras dos Césares: teatro e moralidade nas vidas suetonianas
}

Autor(es): $\quad$ Pimentel, Maria Cristina de Castro-Maia de Sousa

Publicado por: Centro de História da Universidade de Lisboa

URL

persistente:

URI:http://hdl.handle.net/10316.2/23817

DOI:

DOI:http://dx.doi.org/10.14195/0871-9527_19_34

Accessed : $\quad$ 26-Apr-2023 15:16:36

A navegação consulta e descarregamento dos títulos inseridos nas Bibliotecas Digitais UC Digitalis, UC Pombalina e UC Impactum, pressupõem a aceitação plena e sem reservas dos Termos e Condições de Uso destas Bibliotecas Digitais, disponíveis em https://digitalis.uc.pt/pt-pt/termos.

Conforme exposto nos referidos Termos e Condições de Uso, o descarregamento de títulos de acesso restrito requer uma licença válida de autorização devendo o utilizador aceder ao(s) documento(s) a partir de um endereço de IP da instituição detentora da supramencionada licença.

Ao utilizador é apenas permitido o descarregamento para uso pessoal, pelo que o emprego do(s) título(s) descarregado(s) para outro fim, designadamente comercial, carece de autorização do respetivo autor ou editor da obra.

Na medida em que todas as obras da UC Digitalis se encontram protegidas pelo Código do Direito de Autor e Direitos Conexos e demais legislação aplicável, toda a cópia, parcial ou total, deste documento, nos casos em que é legalmente admitida, deverá conter ou fazer-se acompanhar por este aviso.

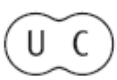



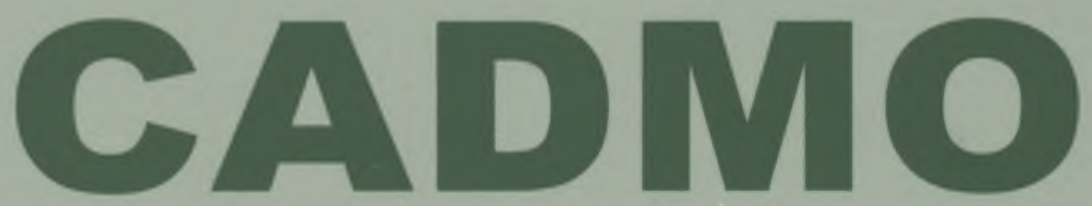

Revista de História Antiga

\author{
Centro de História \\ da Universidade de Lisboa
}

19

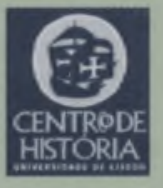

430 =

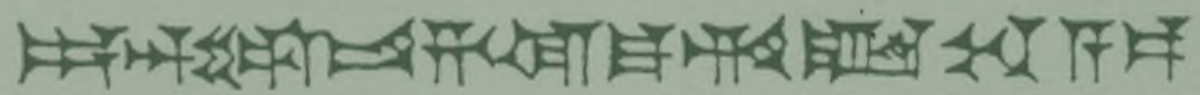

MHNIN AEI $\Delta$ E $\Theta E A ~ \Pi H \Lambda H I A \triangle E \Omega$ 
feminino, aqui estudado através das várias composições que Helena de Tróia tem tido no cinema (sendo este um tema igualmente tratado por nós num colóquio dedicado à heroína mitológica e decorrido em Coimbra em 2006). Cleópatra é outra figura que assume naturalmente contornos mitológicos neste contexto e que o A. sabe aproveitar igualmente bem. De facto, na cultura contemporânea, a última rainha do Egipto assumiu uma posição sem dúvida mítica, em grande parte graças ao cinema. O livro encerra com o regresso à poesia, definida pelas metáforas que Homero e Apolo permitem construir.

Em suma, este livro lida com as representações modernas de temas clássicos, confirmando a importância do Mundo Antigo na cultura contemporânea, sendo de realçar que essas temáticas assumem formas de acordo com os objectivos e os media a que recorrem para se retransmitir e reformular. Apesar de a qualidade do produto não ser sempre homogénea, o certo é que nos basta a presença do tema ou motivo clássico para atestarmos a retransmissão cultural. Winkler classifica pertinentemente essas metamorfoses de "Protean nature". Esta característica confirma ainda o carácter continuamente reinventivo do mito antigo/clássico, falando mesmo num "neo mitologismo" que se pode estudar através de uma ciência a que poderíamos chamar "filmofilologia». Mas será mesmo necessário reinventar o seu nome? Não continuamos no domínio da boa e velha hermenêutica, tout court?

Seja como for, não resistimos a terminar esta recensão com as palavras do próprio Winkler: «if Antiquity is important for cinema, cine$\mathrm{ma}$ is also important for antiquity and the presence of classical Greece and Rome in our culture and education." $\mathrm{Na}$ verdade, quanta da percepção, para não dizer mesmo suposto conhecimento, que as massas possuem do Mundo Antigo, e da Antiguidade Clássica em especial, não será devida ao cinema?

\section{Nuno Simões Rodrigues}

JOSÉ LUÍS LOPES BRANDÃo, Máscaras dos Césares. Teatro e Moralidade nas Vidas suetonianas, Coimbra: Centro de Estudos Clássicos e Humanísticos, 2009, 482 pp., ISBN 978-989-8281-14-2.

O estudo em epígrafe é uma recentíssima edição da biblioteca online Classica Digitalia (http://classicadigitalia.uc.pt): constitui, assim, mais um marco do excelente trabalho que os seus responsáveis vêm 
fazendo em prol da cultura, pondo à disposição de todos um conjunto de obras de reconhecida qualidade no âmbito dos estudos clássicos.

Saúde-se, antes de mais, o facto de se tratar de um estudo sobre Suetónio, autor de que todos falam, mas raramente é lido como merece, e sobre o qual, em língua portuguesa e fora do âmbito das teses académicas, pouco ou nada existe que possa ser de uso para quem aborda as Vidas dos Doze Césares. Tratando-se de trabalho pautado pelo rigor científico, mas também escrito em prosa agradável de ler e de recorte literário, na pureza da linguagem e na correcção do discurso, não podemos senão augurar que ele se torne um dos livros que qualquer professor de literatura latina não hesitará em recomendar aos seus alunos, colhendo também ele, como de resto todos os especialistas na área, um apurado guia para a leitura e interpretação do texto suetoniano. Para tal contribui também o facto de o Doutor José Luís Brandão, a acompanhar os passos latinos que cita, deles ter apresentado - com rigor e elegância - a respectiva tradução. Não ficam assim defraudados os que possam ser mais titubeantes na língua de Cícero. Sublinhe-se ainda a pertinência com que a bibliografia nos é apresentada: extensa, que o é (pp. 393-414), mas absolutamente cingida a títulos que é indispensável conhecer. Merece também uma palavra de louvor a inclusão de três índices (de personagens e lugares históricos; de autores antigos; analítico).

Propõe-se o Autor «perceber o modo como o biógrafo escreve história, como apresenta e manipula as personagens, como julga os governantes e como condiciona o juízo dos leitores" (p. 11). Ao longo da obra, o leitor vai descortinando a materialização e, se assim se pode dizer, o desdobramento destes grandes objectivos em outros que com eles se entrelaçam.

Logo na introdução (pp. 15-27), o Autor lança um repto, o de intentar perceber as razões que levaram Suetónio a escolher um género, a biografia, considerado não tão nobre quanto a história, e isso embora tivesse todas as condições, quer materiais, quer de formação, para se dedicar a labor semelhante ao de Tácito, e de imediato deixa uma pista para a discussão e a hermenêutica do texto: trata-se de um género mais adequado a uma época em que vigorava o governo de um só homem, relativamente à qual Suetónio terá compreendido que eram os uitia e as uirtutes dos imperadores que definiam e conduziam o curso da história. Na mesma introdução, encontramos uma segura contextualização histórica e literária do género biográfico, dos predecessores de Suetónio, na Grécia e em Roma, dos seus modelos 
retóricos. Apetrechado com essa visão do que sustenta e apoia a escolha do biógrafo, pode o leitor abordar as três partes em que se divide o estudo.

A primeira, intitulada "A Construção das Vidas" (pp. 29-91), visa «entender a forma como o biógrafo organiza e apresenta ao leitor o conjunto de informações sobre os imperadores" (p. 31), desvendando as técnicas de conquistar e seduzir um público curioso de conhecer a vida, com seus podres e seus aspectos luminosos, de quem era senhor em Roma, e dono de Roma. Assim se compreende a razão da maior importância da organização da matéria histórica per species, por rubricas, com grande vantagem sobre a apresentação cronológica, per tempora, que todavia Suetónio não rejeita, particularmente quando se ocupa do nascimento e das circunstâncias da morte dos imperadores. $\mathrm{Na}$ análise do par uirtutes/uitia, descortina José Luís Brandão os meios de captação do leitor, entre eles, para darmos apenas dois exemplos, o recurso aos rumores e à anedota, e a intervenção directa do autor no texto.

$\mathrm{Na}$ segunda parte, a mais extensa, sob o título "O Teatro das Vidas» (pp. 93 325), analisa-se a obra de Suetónio na perspectiva da importância que o teatro assumia na propaganda imperial. Para isso esmiúça-se a presença de elementos dramáticos na construção das biografias, mostrando como e por que razão nelas se dá um óbvio relevo aos dramas pessoais e privados, em detrimento dos colectivos e públicos. Prova-se que cada Vida é como que uma peça "com princípio, meio e fim, em que o biografado é o protagonista” (p. 95), com as suas acções e os seus dicta, com os actores secundários que o rodeiam, e vivem e agem em função dele. Nesse drama, acompanha José Luís Brandão, em momentos sucessivos, a ascensão (gloriosa, controversa ou inglória) dos imperadores, expressa segundo os parâmetros que hão-de nortear a sua conduta enquanto principes, a conquista e recepção do poder supremo, o exercício do poder, e, finalmente, a morte, vista seguindo o prisma que faz com que "os bons imperadores [sejam] premiados com mortes dignas" (p. 271) e que os maus sofram, na morte, as consequências da maldade ou do destempero com que urdiram o seu governo. Nessa conformidade, José Luís Brandão observa até que ponto, no desvendar das máscaras que os principes envergavam, Suetónio pretendeu, mais do que delectare, também mouere e docere.

$\mathrm{Na}$ terceira parte, «A expressão da moralidade: Juízos e Prejuízos" (pp. 327 380), prova se que as Vidas «transmitem uma men- 
sagem não tanto política como moral» (p. 329) e que, por isso, Suetónio não é, ao contrário do que muitos dizem e escrevem, um autor meramente descritivo, que se abstém de tirar ilações de âmbito moral, deixando-as para o leitor. Para intervir, manipula pois os dados históricos, escolhendo, deturpando ou omitindo, em função dos valores que quer enaltecer ou dos vícios que quer exprobrar, com a clara intenção de "condicionar e atrair o leitor para a sua mensagem moral» (ibidem). Não andam aqui ausentes os princípios da fisiognomonia que, se não é uma ciência exacta, pelo menos é a arte que permite a Suetónio conceber o retrato físico dos imperadores como reflexo do ethos.

Assim se prova que os objectivos de Suetónio eram tudo menos os triviais de uma má língua ou de um ajuste de contas com os imperadores desaparecidos. O que se apresenta são modelos, modelos a seguir e modelos a rejeitar, na "representação do extremo ao qual determinado vício ou determinada virtude podem conduzir» (p. 389), para usar palavras da Conclusão (pp. 383-390) deste estudo, tal como se prova que a arquitectura das Vidas não se compadece com leituras truncadas ou observação de excertos. José Luís Brandão leva-nos a ver que as doze biografias devem ser "lidas de forma continuada", pois "[s]ó assim se podem abarcar plenamente as qualidades literárias e os objectivos do biógrafo" (p. 390). E é nessa leitura que nos propõe que verificamos a justeza do juízo dos séculos, que fizeram de Suetónio um dos leitores mais lidos, e mais apreciados, de toda a literatura latina.

\section{Maria Cristina de Castro-Maia de Sousa Pimentel}

ESTEBAN CALDERÓN DORDA, ALICIA MORALES ORTIZ (eds.), La madre en la Antigüedad: Literatura, Sociedad y Religión, Madrid: Signifer Libros, 2007, 276 pp., ISBN 978-84-934612-9-4.

O volume coordenado por Esteban Calderón e Alicia Morales, intitulado La madre en la Antigüedad: Literatura, Sociedad y Religión, apresenta-se como uma colectânea de ensaios sobre a maternidade e a figura da mãe no mundo grecolatino e cuja intenção monográfica se cumpre por meio da análise do tema em textos de distintos géneros do espaço literário grego e latino. O volume é ainda complementado por dois textos centrados na mundividência bíblica do tema da mater- 